\title{
Is a tailored work-related support intervention feasible in everyday clinical practice? The experience of healthcare professionals and patients with cancer
}

\author{
AnneClaire G.N.M. Zaman ${ }^{\mathrm{a}}$, Kristien M.A.J. Tytgat ${ }^{\mathrm{b}}$, Jean H.G. Klinkenbijl ${ }^{\mathrm{c}}$, \\ Monique H.W. Frings-Dresen ${ }^{\mathrm{a}, 1}$ and Angela G.E.M. de Boer ${ }^{\mathrm{a}, 1, *}$ \\ ${ }^{a}$ Amsterdam UMC, University of Amsterdam, Coronel Institute of Occupational Health, Amsterdam Public Health \\ Research Institute, Amsterdam, The Netherlands \\ ${ }^{\mathrm{b}}$ Amsterdam UMC, University of Amsterdam, Department of Gastroenterology, Amsterdam, The Netherlands \\ ${ }^{\mathrm{c}}$ Gelre Hospitals, Department of Surgery, Apeldoorn, The Netherlands and University of Amsterdam, Amsterdam, \\ The Netherlands
}

Received 31 October 2018

Accepted 29 July 2019

\begin{abstract}
.
BACKGROUND: Work is valued as an important feature in life, however patients diagnosed with cancer can experience work-related problems. We developed a work-related support intervention to support those in need.

OBJECTIVE: The objective of this study was to evaluate the feasibility of the performed tailored GIRONA (Gastro Intestinal cancer patients Receiving Occupational support Near and After diagnosis) intervention and to describe the experiences of those receiving the work-related support and of those providing it.

METHODS: An online questionnaire was used to survey the feasibility of the intervention of the support recipients (patients diagnosed with gastrointestinal cancer) and the support providers (healthcare professionals including: oncology nurses and oncological occupational physicians). Five themes were covered: acceptability, demand, implementation, practicality and integration of Bowen's feasibility model.

RESULTS: Twenty-three patients, 14 oncology nurses and 4 oncological occupational physicians, shared their experiences about the tailored work-related support intervention. This intervention was generally perceived as positive and feasible by the participants. Some patients received work-related support despite not experiencing severe problems; others mentioned that they received no such support even though they did need it. Despite positive experiences, there are some barriers to tackle, such as length of consultation, timing of the initiation of work-related support and embedding the oncological occupational physician within the clinical setting.

CONCLUSION: According to the healthcare professionals involved, GIRONA is feasible, however some practical barriers were mentioned. The intervention was perceived as positive by both patients and healthcare professionals, but the tailored component could be further improved to better support those in need of work-related support.
\end{abstract}

Keywords: Return to work, gastrointestinal neoplasms, vocational rehabilitation, patient care, feasibility studies

\footnotetext{
${ }^{1}$ Monique H.W. Frings-Dresen and Angela G.E.M. de Boer contributed equally to this paper as principal investigators.

${ }^{*}$ Corresponding author: Angela G.E.M. de Boer, E-mail: a.g.deboer@amsterdamumc.nl.
}

\section{Introduction}

Cancer will affect most people at some point in their lives, either personally or through a close relative. In a study by Ahmad et al. [1] the probability of 
being diagnosed with cancer in Great Britain (only excluding non-melanoma and skin cancer) was estimated for men and women born since 1960. The results of their study was that one in two persons will be diagnosed with cancer under the age of 65 [1]. Hence, at an age that a person typically participates as part of the labour force in the Netherlands [2]. Due to national screening programmes aimed at cancer identification such as colorectal cancer [3], more people being diagnosed with cancer are now diagnosed at an earlier stage and so chances of survival are improving - as are treatments $[4,5]$, which do lead to better survival rates. Furthermore, the raised retirement age, contributes to the fact that more patients diagnosed with cancer are of working age (18-67 years) $[2,6]$.

Patients diagnosed with cancer often value work as important to them in a positive way, for example by giving them a sense of 'feeling normal' $[7,8]$. Studies have shown that patients diagnosed with cancer receive little guidance from their physicians about their ability to work and return to work (RTW) [9-11], or conflicting information regarding their ability to work and RTW [12]. However, it is known from earlier research that many start experiencing work-related problems as soon as they are diagnosed [13]. In recent years, studies regarding work-related support in the clinical setting were developed [14-17]. Despite those recent developments, there still is a relative lack of research related to work and RTW by cancer patients, especially studies looking at support immediately after diagnosis and at work-related support tailored to the individual. Therefore, we developed a tailored work-related support intervention named GIRONA (Gastro Intestinal cancer patients Receiving Occupational support Near and After diagnosis), which was performed and evaluated using a multi-centre randomised controlled trial (RCT) [18, 19]. It encompassed an intervention in which tailored work-related support is provided to patients aged 18-63 diagnosed with curative gastrointestinal (GI) cancer. Patients were randomised to the control (usual care) or invention group (tailored work-related support). Colorectal cancer is one of the most common of all cancer diagnoses, but other GI cancers - including stomach, liver, pancreatic and oesophageal cancer - are also amongst the 15 most common types worldwide [20].

The innovative aspect of the GIRONA intervention is that work-related support: 1) begins early after diagnosis; 2) is tailored to the severity of patients work-related problems; and 3) the healthcare professional supporting the patient is assigned based on the severity of the work-related problems accordingly.

A complex intervention requires a feasibility study to determine whether it is likely to work effectively in everyday clinical practice [21] by identifying potential barriers and strengths, and by assessing the practical applicability of its outcomes [22]. Moreover, optimum implementation requires that perspectives of various stakeholders in the intervention converge [23]. In our study, therefore, we have paid particular attention to the experiences of all the stakeholders involved, both those providing the work-related support and those receiving it. Their involvement with the intervention, on the providing and receiving respectively, makes their expertise important because they are the persons best placed to indicate whether it is useful. In addition, such stakeholder engagement ensures broad support for the exercise.

The objectives of this study, therefore, were to evaluate the feasibility of the GIRONA intervention and to describe the experiences of those providing (healthcare professionals) and receiving (patients) work-related support through this intervention.

\section{Methods}

\subsection{Study design}

We have performed a feasibility study of the GIRONA intervention. Patients who participated in the GIRONA study were approached for this feasibility follow-up study. Those who confirmed their participation received the feasibility study questionnaire. The questionnaire was developed using the model of Bowen [22], to gather information of patients and healthcare professionals.

The questions included answers-options which were quantitative data (see Appendix 1 for examples). These questions were followed by open-ended questions, as an addition to their answers. Therefore, this study had mostly a qualitative design and was analysed using content analysis [24, 25].

Consequently, to report important aspects of the qualitative research, items from the Consolidated criteria for REporting Qualitative research (COREQ) checklist [26] were used. By using the checklist, necessary components of the study are comprehensively reported and helped to structure them. 
Table 1

GIRONA feasibility study invitees and participants

\begin{tabular}{lccc}
\hline & $\begin{array}{c}\text { Participated in the } \\
\text { GIRONA study }\end{array}$ & $\begin{array}{c}\text { Invited for the } \\
\text { feasibility study }\end{array}$ & $\begin{array}{c}\text { Participated in the } \\
\text { feasibility study }\end{array}$ \\
\hline $\begin{array}{l}\text { Patients } \\
\text { Healthcare professionals }\end{array}$ & $88^{\mathrm{a}}$ & 30 & 23 \\
$\quad$ & 7 & $4^{\mathrm{b}}$ & 4 \\
Oncological occupational physicians & 35 & $31^{\mathrm{c}}$ & $14^{\mathrm{d}, \mathrm{e}}$ \\
\hline
\end{tabular}

a Participants from the randomised controlled trial; only patients randomised to the intervention group were invited for this study, and only if they had stated on their original informed consent form that they were willing to be approached for follow-up research. ${ }^{\mathrm{b}}$ Only those oncological occupational physicians who did actually hold support meetings with patients were invited. ${ }^{c}$ During the ongoing GIRONA research, there was some turnover of nurses within the participating hospitals and not all responded to the invitation e-mail. ${ }^{\mathrm{d}}$ Oncology nurses who either did actually hold support meetings with patients $(\mathrm{N}=8)$ or were otherwise closely involved with the GIRONA intervention $(\mathrm{N}=6) .{ }^{\mathrm{e}}$ Nurses were from nine different hospitals in the Netherlands.

\subsection{The GIRONA intervention}

The intervention consists of psychosocial workrelated support [18, 19]. Items discussed in the support meetings were for example contact with colleagues and employer about the reason of their absence, the possibility to work during treatment, information about the importance of work and some key decision points in the process of reporting sick (the Improved Gatekeeper Act).

The intervention included a maximum of three individual face-to-face meetings lasting 30 minutes each, and the first meeting was scheduled prior to the start of the treatment [18]. Since work-related problems can differ in severity, the intervention itself was split into three types of support (support A, B and C) [18], in order to tailor the support to meet the needs of individual patients. Referral was based on certain possible contributing factors to work-related problems, described in a decision diagram (see Appendix 2 for the factors included), for example pain in relation to work which will be discussed in support $\mathrm{A}$ and lack of support from colleagues and employer in support B. Within each support type, the kind of healthcare professional assigned to provide supportive care was tailored to the severity of the work-related problems. In support A this was an oncology nurse, in support B an oncological occupational physician and in support $\mathrm{C}$ a multidisciplinary team (including at least an oncology nurse, the treating physician and an oncological occupational physician).

The intervention is described in a study protocol and published separately [19], and administered in the Dutch trial registry (NL4920/NTR5022).

The possible contributing factors to the patients' work-related problems were determined from the baseline questionnaire they filled out in the beginning of the GIRONA study. The researcher used the decision diagram to determine the type of support to which the patient should be referred [18]. As per protocol, the professional used the decision diagram at the end of the second meeting to evaluate whether the type of support being provided was still appropriate. During the study, no patient was eligible for support type $\mathrm{C}$ (by a multidisciplinary team) as initially determined using the decision diagram.

\subsection{Ethics statement}

The Medical Ethics Review Committee of the Academic Medical Center (AMC), Amsterdam approved the study under registration number W17_312\#18. 365. The committee considered that the Medical Research Involving Human Subjects Act did not apply to the feasibility study and that the committee's formal approval was not required.

\subsection{Participants}

Those patients who participated in the GIRONA study and who had stated on their informed consent form that they were willing to be approached for follow-up research were invited to take part in this feasibility study $(\mathrm{N}=30)$. The healthcare professionals invited were those who provided the intervention during the GIRONA study, both oncological occupational physicians $(\mathrm{N}=4)$ and oncological GI nurses $(\mathrm{N}=31)$.

The recruitment of participants (Table 1) for this feasibility study occurred between November and December 2017.

\subsection{Procedure}

Patients were initially contacted by telephone by the first author. The aim, procedure and duration of 
the study were explained, after which they received an e-mail with further information. All the professionals were invited by e-mail, with a description of the aim, procedure and duration of the study, and could register to participate in the study by replying to it. One reminder was sent to those who did not respond, after one week.

\subsection{Informed consent}

Once a patient or professional had confirmed their willingness to participate, they received an online informed consent form compiled using the questionnaire system, Qualtrics (www.qualtrics.com). A digital signature was requested to confirm their participation. Some patients preferred paper versions of informed consent form and questionnaire and received therefore per post (including a retour envelope).

\subsection{Questionnaire}

To assess the feasibility of the intervention, five areas of focus from Bowen's model were surveyed: 1) acceptability; 2) demand; 3) implementation; 4) practicality; and 5) integration. Bowen [22] described eight such areas of focus, but we excluded 'adaptation', 'expansion' and 'limited efficacy' because they did not apply to our intervention study.

The first area of focus in Bowen's model, acceptability 1), is divided in two subcategories: satisfaction (with the work-related support provided and received) and perceived appropriateness (did the patient experience the support received as useful and what were the healthcare professionals' opinions of the decision diagram). The patients' were also asked if they were supported by an appropriate healthcare professional. The second area is demand 2). Questions were asked to determine if the tailored support was actually likely to be used. Was there a demand for it from the patient, the healthcare professional and/or the clinical setting? In the third area, implementation 3), questions addressed the decision diagram to evaluate whether, from the healthcare professionals' perspective, this referred the patient to the right support type. Next came practicality 4), subdivided into questions about the intervention in general and the decision diagram in particular. Healthcare professionals were asked if they were able to support the patients and/or if the work-related support was too complex for them. The final area of focus was integration 5). Questions were asked about future prospects of, barriers and facilitators of this form of work-related support within the clinical setting.

Since several groups participated in the study: patients, oncological occupational physicians and oncology nurses, separate questionnaires with appropriate questions were developed for each.

\subsection{Pilot test questionnaire}

The questionnaires were tested by two members of the project group [AZ and $\mathrm{AdB}]$ and a colleague with experience of the Qualtrics system for legibility, structure and logical-skip questions.

The final questionnaires were sent to the participants between November 2017 and January 2018 after informed consent form was received.

\subsection{Analysis}

Data from Qualtrics was exported to SPSS (IBM SPSS Statistics 24) and MAXQDA (MAXQDA 12). Descriptive analysis was used to answer questions in 'yes' or 'no' terms by means of frequency tables and complemented with a qualitative analysis of the comments entered under the subquestions. The qualitative coding analysis was performed by two researchers [AZ and AdB], with its themes identified in advance using the questionnaire questions as a coding tree. In other words, a deductive approach was used. Participants did not receive feedback on their answers.

\section{Results}

In total,16 Dutch hospitals across the Netherlands participated in the intervention study. For this feasibility study the questionnaire was filled out by (1) patients who have received work-related support $(\mathrm{N}=23)$; and (2) healthcare professionals who have provided it; (a) oncological occupational physicians $(\mathrm{N}=4)$ and (b) oncology nurses $(\mathrm{N}=14)$. Patient characteristics are summarised in Table 2.

Our findings on the feasibility of the intervention are presented per area of focus of the in Bowen's model: acceptability, demand, implementation, practicality and integration [22].

\subsection{Acceptability}

In general, both healthcare professionals and patients were satisfied with the work-related support intervention. One oncological occupational physician 
Table 2

Baseline characteristics of participating patients in the feasibility study

\begin{tabular}{|c|c|c|}
\hline & $\begin{array}{l}\text { Support type A } \\
\mathrm{N}=13\end{array}$ & $\begin{array}{c}\text { Support type B } \\
\mathrm{N}=10\end{array}$ \\
\hline Gender & 10 Male & 4 Male \\
\hline Mean age (SD) & $58(4.8)$ & $53(9.3)$ \\
\hline \multicolumn{3}{|l|}{ Marital status } \\
\hline $\begin{array}{l}\text { Married/living together } \\
\text { with partner }\end{array}$ & 12 & 9 \\
\hline Single & 1 & 1 \\
\hline Divorced/widower & - & - \\
\hline \multicolumn{3}{|l|}{ Type of cancer } \\
\hline Colon cancer & 11 & 8 \\
\hline Rectal cancer & 2 & 2 \\
\hline \multicolumn{3}{|l|}{ Main wage earner } \\
\hline Yes & 6 & 3 \\
\hline No, my partner is & - & 1 \\
\hline Equal with partner & 7 & 5 \\
\hline \multicolumn{3}{|l|}{ Work contract } \\
\hline Permanent employment & 12 & 9 \\
\hline Temporary employment & 1 & - \\
\hline Self-employed & - & 1 \\
\hline \multicolumn{3}{|l|}{ Occupational sector* } \\
\hline Industry (A) & 1 & 1 \\
\hline Construction $(\mathrm{F})$ & 1 & - \\
\hline Wholesale and retail $(\mathrm{G})$ & 1 & - \\
\hline $\begin{array}{l}\text { Information and } \\
\text { communication }(\mathrm{J})\end{array}$ & 2 & - \\
\hline Financial institutions (K) & 1 & 1 \\
\hline $\begin{array}{l}\text { Consultancy, research and } \\
\text { other specialist business } \\
\text { services (L) }\end{array}$ & - & 1 \\
\hline $\begin{array}{l}\text { Rental and other business } \\
\text { services }(\mathrm{N})\end{array}$ & 3 & 1 \\
\hline Education $(\mathrm{P})$ & 2 & 2 \\
\hline Health and welfare (Q) & 1 & 3 \\
\hline $\begin{array}{l}\text { Other service households } \\
\text { and extraterritorial } \\
\text { organisations }(\mathrm{T})\end{array}$ & 1 & 1 \\
\hline
\end{tabular}

* Standard Industrial Classifications according to the Dutch Standaard Bedrijfsindeling (SBI) based on the classifications of the European Union (NACE) and United Nations (ISIC).

indicated that, although he was satisfied overall, there were some barriers such as the time available for a consultation. Another stated:

'I have certainly been able to give patients advice or motivate them to find the right solutions for the obstacles experienced.' (OOP1)

However, an oncology nurse did mention, with regard to her role in the intervention, that:

'Ultimately, the decisions rest with the occupational physician or employer, so my support is of limited value.' (ON1)

The majority of patients were satisfied with the intervention. One commented:
'Satisfied, although I would be more satisfied if support were closer, at my own hospital and more frequent - monthly, for example.' (P4)

However some patients were not satisfied, as one explained:

'Very dissatisfied - I do not think I have had any support.' (P20)

The oncological occupational physicians were mainly positive about the perceived appropriateness of the intervention, indicating that the patients experienced the work-related support provided as useful. The nurses were more divided, in particular because some had only a few intervention meetings. Also, one nurse had the idea that some patients already received sufficient support in their work environment.

'It is a difficult question, I would rather answer this with neutral. I didn't have many interventions meetings and people experienced sufficient support from the working environment.' (ON2)

Both oncological occupational physicians and nurses were moderately positive about the usefulness of the decision diagram. Half of the oncological occupational physicians had used the decision diagram, although they were neutral about that use (answer categories were: good-neutral-bad-too difficult-not clear). One stated in the comments:

'The decision diagram was not applicable to everyone. The patient journey, intervention and diagram were not always in step.' (OOP4)

The majority of the oncology nurses used the decision diagram. Half of them scored its usefulness as 'good'. Some referred patients to another support type.

Patients were asked if they felt the professional they were assigned was qualified to provide the support they needed, or if they should have been supported by another type of professional. In general, they were positive about 'their' healthcare professionals.

'[She had] knowledge about cancer, knowledge about mental barriers. Looked at the whole picture, came up with concrete things that helped.' (P4, patient on support from oncological occupational physician)

'[She] was skilled and understood the situation.' (P23, patient on support from oncology nurse) 
However, there were some exceptions: patients who indicated that they had received little or even no support. One responded that it would have been better to have been helped by an oncological social worker.

We next asked patients if they had the idea they had returned to work earlier due to this intervention, or experienced fewer work-related problems as a result of it. Few of those who answered this question indicated that they had not returned to work earlier, although some did state that their return was fairly quick because they were offered greater flexibility (e.g., opportunities to work at home). Another patient indicated that he had contacted his own occupational physician to compile a timetable for his RTW. In addition, some patients gave feedback that there should be more understanding from their employer.

\subsection{Demand}

In this area of focus we evaluated whether tailored support is actually likely to be used. One oncological occupational physician emphasised that there is indeed a demand for work-related support from the patient's perspective:

'That's evident from nearly all my conversations

[with patients] - people struggle.' (OOP1)

Conversely, this kind of work-related support (within the clinical setting) is difficult to provide as an oncological occupational physician. One challenge is the logistics of the intervention. Apart from that, however, the oncological occupational physicians described positive experiences.

Patients also described positive experiences, appreciating the oncological occupational physician expertise with the combination of cancer and workrelated problems.

It is noted that work-related support in general is of importance, although at the same time it is important to look at patients specifically. One oncology nurse said:

'An informative support meeting is useful for every patient of working age. Whether the followup meetings are useful depends on how things unfold.' (ON1)

Another nurse indicated that the intervention has a positive effect for the whole department. That patients are able to tell their story about the work-related aspects of their condition is an important step in itself.
They feel they are being supported. Yet some have a different opinion regarding the future of the intervention, with one stating that they had gained no benefit from the support provided and others mentioning that it is closely related to the particular moment and situation. One expressly indicated a willingness to receive this type of support again at the moment of the interview.

\subsection{Implementation}

In this area of focus we asked the healthcare professionals if they used the decision diagram to evaluate whether the patient was receiving appropriate support or needed another type available within the intervention. As mentioned under 'acceptability', they were generally positive about the decision diagram. One oncological occupational physician stated that it was good to use in a research setting, but was unsure whether it would support her in everyday practice. Reasons why the decision diagram was not used included the patient already having returned to work before the second meeting. Unfortunately, there were also some 'no shows', so those meetings had to be cancelled.

\subsection{Practicality}

This area of focus concerns the means whereby the intervention is provided, now and in the future. It was separated into the practicality of the intervention in general and that of the decision diagram in particular. The healthcare professionals were asked if they were able to support the patients with the factors from the decision diagram and/or if the work-related support was too complex for them.

One oncology nurse mentioned that the workrelated support is practical now because of the setting provided by this study. However, it may become a more difficult task if introduced into everyday practice without the study setting context.

'To take part in this study, an exception has been for these patients. But were this to become "standard" care, these extra consultations might difficult to organise.' (ON1)

One oncological occupational physician mentioned that no factors made work-related support impossible as such, although as a medical practitioner there are practical barriers related to consultation length, location and multidisciplinary co-operation. There are definitely some hurdles to be 
overcome, as another oncological occupational physician explained:

'That [the intervention] is not a problem in itself, but in these cases it is important to be able to consult other parties - other medical practitioners, for example - and that did not always prove possible. This makes it important to be closer to the clinic (or even in it) when providing work-related care.' (OOP1)

Based on the factors listed in the decision diagram, patients are assigned to one of the three different types of support available (A, B and C). In general, oncology nurses can support those with the determining factors for type A: pain, fatigue, uncertainty about the future and support from family in relation to work-related problems. The oncological occupational physicians also mentioned that they could support the patients with the determining factors for type B: workplace support, cognitive problems, side effects and an accumulation of other factors (number of working hours, treatment, stage of cancer and fatigue) in relation to work-related problems.

The healthcare professionals were asked if they agreed on the factors listed in the decision diagram and the way they are used to assign a patient to support type A (by an oncology nurse), B (by an oncological occupational physician) or C (by a multidisciplinary team). As one oncology nurse pointed out, it is difficult to tell whether all patients were correctly assigned because there were not many of them and so it was hard for a nurse to develop the necessary experience.

One oncological occupational physician had a comment about the classification of the factors for assignment to support type A as they relate to the oncology nurse providing that support:

'In the case of fatigue, for example, a good medical, psychosocial and occupational analysis of the problem is important. The question is the extent to which the oncology nurse can do this. In my opinion it is important that care take place in a good [clinical] chain, so that the oncology nurse can fall back on experts if necessary.' (OOP3)

On the question of whether the support is too complex, one nurse answered that she found questions about long-term sick leave difficult. Furthermore an oncological occupational physician stated that the support is too complex for the limited time available to provide it (for this research, consultations were limited to 30 minutes). A comment from an oncology nurse recommended that all self-employed patients should receive support from an oncological occupational physician by default.

\subsection{Integration}

Finally, integration is about the intervention's perceived 'fit' within the existing clinical system and its sustainability. The terms 'relevant' and 'meaningful' were used repeatedly by the healthcare professionals to describe the intervention, although the oncology nurses were slightly more reserved in this respect than the oncological occupational physicians. With regard to future work-related support, we asked the professionals whether they would like to continue providing it. Overall, they agreed that it is important that it be maintained.

However, both oncological occupational physicians and nurses mentioned some barriers. First of all, the time available for the meetings - approximately 30 minutes - was too short for the oncological occupational physicians. Nurses tend to know their patients, because they support them from the moment they get diagnosed and they follow the patient during their treatment process. Therefore, the nurse is familiar with the medical and personal-related history from the beginning. However, the oncological occupational physician has to start from scratch with the patient's medical and occupational history, and as such, they are a new professional in the clinical setting introduced to the patient at a certain moment for this research.

This leaves little time left for the intervention itself, to support the patient's self-management of their work situation or RTW or to communicate with the other healthcare professionals.

'Contact with the treatment team and the patient's own occupational physician is not really feasible within the limited time available, and also difficult to achieve logistically. If the patient is not good at self-management, then it's asking far too much.' (OOP3)

Another major barrier for the oncological occupational physicians is financial support. This kind of care is not yet covered by standard Dutch medical insurance, which basically means that the oncological occupational physicians have to provide it on a voluntary basis.

Work-related support is feasible, however outside the research context, time for the patient is a precious commodity in everyday clinical practice. One nurse 
said that because this kind of work-related support is important, it should be recognised by the hospital in general. At present, though, it is given little or no consideration. One oncological occupational physician mentioned a need for easily accessible collegial consultations, which were not feasible during this study for logistical reasons.

Suggestions for improvement from the healthcare professionals included bridging the gap between hospital treatment and RTW, enabling the oncological occupational physician to translate information from primary care concerning work-related problems to help in the patient's transition to that of their regular occupational physician (although this would require the patient's consent) and making the oncological occupational physician part of the multidisciplinary treatment programme within the clinical setting. Finally, one important item mentioned by both oncology nurses and oncological occupational physicians was the length and timing of the support consultations.

\section{Discussion}

The objective of this study was to evaluate the feasibility of the GIRONA intervention using the experiences of those receiving the work-related support (patients) and of those providing it (healthcare professionals). In both cases, these experiences were overall positive. Our findings highlight the importance of tailoring the intervention because not every patient is the same, their needs are different and so the support they receive needs to be adjusted accordingly. Although we did perform a tailored intervention, the patient responses indicate that these could have been adapted even more to their individual needs. In general, the support was perceived as appropriate. Both patients and healthcare professionals said that it added value to the 'standard' care provision. We can therefore state that it is feasible to provide tailored work-related support to patients diagnosed with a curative GI cancer. Some barriers - in respect of the length and timing of consultations, for example - do need to be overcome in order to provide this kind of support in everyday clinical practice.

Unfortunately there is still a lack of research about tailored early work-related support interventions after a cancer diagnosis, and their efficacy. The review by de Boer et al. [7] underlined this gap. We developed and evaluated a tailored work-related intervention for patients with gastrointestinal cancer. The first element to mention about the GIRONA intervention, was the provision of patient support prior to the start of treatment. It is known from earlier research that patients experience work-related problems early in their treatment phase [13], but also that it is not a priority in the clinical setting [27] and little workrelated guidance is received by patients from their treating physicians $[9,10]$.

The oncology nurse plays an important role in the GIRONA intervention because they see patients after the moment of diagnosis and in the early stages of the treatment process. Research about early interventions is scarce [7, 28]. Our findings from this feasibility study indicate that the oncological occupational physicians agree that work-related support should begin 'before start of the cancer treatment', although some nurses indicated that it was too early. Knott et al. [29] conclude that, despite timing of RTW is an important issue, it has yet to gain sufficient prominence in the literature. So, we emphasise that workrelated support needs to be tailored to the specific patient's needs. We therefore need the experience of healthcare professionals to monitor those patients in need of work-related support. This is also emphasised by Kiasuwa [30], who concludes that there is an important role for the healthcare professionals within the clinical setting as regards early screening for work-related support needs and the referral of patients with them. However, those professionals lack adequate tools and training to undertake such screening effectively. This is also apparent from our study, in which the decision diagram is introduced as a tool for an initial screening including factors that might lead to work-related problems and so are important to discuss with the patient. Since it is important too, that the healthcare professional gain an insight into which patients actually develop work-related problems, they should be trained in this aspect as well.

The second element of the GIRONA intervention is the tailored component: individualised work-related support. Wells et al. [31] pointed out that interventions need to be tailored to the patient where acknowledgment of the individual work-related outcome is important. In their model they showed the complexity of the situation, with four key aspects interacting: self-identity, meaning and significance of work, family and financial context and work performance and environment. In the GIRONA intervention, these aspects are discussed in the support meetings. However, we have to acknowledge based on our results, that support needs be tailored even more to the individual since some patients stated that 
they did not had the feeling they were supported at all, whilst others said that they had experienced no work-related problems. Both of these responses can be attributed in part to the support-type selection process and the decision diagram used in it.

Furthermore, to individualise work-related support, the third element of the GIRONA intervention, is the assignment of a healthcare professional in line with the severity of the problems experienced. Our study provided three types of support: A (mild workrelated problems, supported by the oncology nurse), B (severe work-related problems, supported by the oncological occupational physician) and $\mathrm{C}$ (complex work-related problems, with support by a multidisciplinary team). In the end, no patients were referred to support type C.

We can conclude that patients in general experienced the work-related support provided by the nurses or/and oncological occupational physicians as positive.

In the literature, there is no consensus about which healthcare professional should provide early workrelated support within the clinical setting. Petersen et al. [27] explored the experiences of healthcare professionals involved in RTW interventions during cancer treatment. Patients were informed about the intervention by physicians and nurses. The first meeting was held at a municipal job centre, with social workers. Support was tailored in line with the patients' answers in the baseline questionnaire about their readiness for RTW and their support needs. One finding of this study was that work-related issues are not a common everyday topic of clinical conversation for healthcare providers [27]. Concomitant with this result, a proportion of the nurses in our study stated that they found it difficult to support patients, especially those with more severe work-related problems, despite having received training to do so. Whilst acknowledging its importance, they found this task challenging because, as per Petersen's findings [27], there was no routine in their everyday practice for discussion of work-related problems and RTW.

Bains et al. [14] assessed the feasibility of an RTW intervention for colorectal cancer patients. Performed during the treatment phase, this included a one-to-one guidance meeting with the researcher and an educational leaflet supporting RTW. This study also raised the issue of which type of healthcare professional should be designated to deliver the work-related support. Participants indicated that such practitioners as specialist nurses, consultants or occupational health professionals should provide support in solving work-related problems. As well as the oncology nurse, in our study we included the oncological occupational physician as a possible support provider. They play an important role in the GIRONA intervention because of their knowledge of work-related problems and of legislation related to sick leave as well as their experience of patients diagnosed with cancer. This know-how was appreciated by patients in our study, who responded positively to the physician's combination of specific workrelated knowledge their understanding of problems related to cancer treatment. Moreover, the structure of the GIRONA intervention- with different types of support depending on the severity of the patient's work-related problems, and the possibility of switching between them to meet specific support needs at any given moment (tailoring) - allows the oncological occupational physician to provide nurses with back-up as and when they require advice or when the patient needs to be referred to an expert with more occupational health expertise. After all, nurses have no specific training about work-related problems, RTW issues or legislation around sick leave. Unfortunately, though, logistical and financial constraints continue to block oncological occupational physicians from providing this kind of care within the clinical setting.

One strength of our study is that we have used an existing clinical setting and involved several kinds of healthcare professionals, who reinforce each other in their clinical practice. Oncology nurses already active in the clinical setting, whilst the second-line professional was the oncological occupational physician with expertise in both work-related problems and those associated with and cancer and its treatment.

On the other hand, one limitation in the study is the allocation of patients to one of three types of work-related support (A, B or C). Here, the main concern is that no patients at all were referred to type $\mathrm{C}$. This means that there are no meaningful statements about the feasibility of support by a multidisciplinary team. Despite that, however, we do believe that this is an important component of the overall spectrum of work-related support provision. This is precisely because of its multidisciplinary character, with cooperation between various healthcare professionals. After all, the usual rehabilitation trajectory of patients diagnosed with cancer is a dynamic one involving several different healthcare providers. With that in mind, the position of the oncological occupational physician should be recognised in order to encourage co-operation within the clinical setting. 


\section{Conclusion}

In this feasibility study we have integrated different perspectives, from those providing work-related support and those receiving it. From the encouraging results obtained, we now know that in everyday clinical practice we have to focus more on the timing of the support provided and on tailoring it to patients' individual needs. Whilst the research setting gave us the opportunity to incorporate the oncological occupational physician in this intervention scenario and made it possible for them and oncology nurses to schedule their consultations in advance, that is not necessarily the situation in everyday clinical settings and so we need to further investigate how to maintain work-related support in 'normal' clinical practice. Knowledge about early work-related support of this kind has to be distributed widely, and hospitals need to acknowledge that it is an integral part of the treatment process. Only then will oncology nurses be given more consultation time to provide such psychosocial support and oncological occupational physicians more capacity to embed themselves in the clinical setting. One obvious practical upshot of this scenario is that nurses should receive more specific training about work-related problems, RTW issues $[12,32]$ and legislation around sick leave in order to improve their basic knowledge and empower them to monitor patients in need of support in these areas.

\section{Author contributions}

All five authors (AZ, AdB, MF, KT, JK) were responsible for the content of the questionnaires. $\mathrm{AZ}$ and $\mathrm{AdB}$ tested the online questionnaires. AZ and $\mathrm{AdB}$ were responsible for data analyses. $\mathrm{AZ}$ was responsible for data collection and the draft manuscript. All authors have read and corrected draft versions of the manuscript and approved the final version.

\section{Conflict of interest}

None of the authors have any conflict of interest to report.

\section{Funding}

This study was supported the Dutch Cancer Society under Grant UVA2012-5619.

\section{References}

[1] Ahmad AS, Ormiston-Smith N, Sasieni PD. Trends in the lifetime risk of developing cancer in Great Britain: comparison of risk for those born from 1930 to 1960 . Br J Cancer. 2015;112(5):943-7.

[2] Uitvoeringsinstituut Werknemers Vezekering (UWV) (in English: Institute for Employee Insurance) AOW-leeftijdberekenen (in English Retirement age- calculator). Available from: https://www.uwvpensioen.nl/aow-leeftijdberekenen. Assessed: Feb 2019.

[3] Navarro M, Nicolas A, Ferrandez A, Lanas A. Colorectal cancer population screening programs worldwide in 2016: An update. World J Gastroenterol. 2017;23(20):3632-42.

[4] Christensen K, Doblhammer G, Rau R, Vaupel JW. Ageing populations: the challenges ahead. Lancet. 2009;374(9696):1196-208.

[5] Karim-Kos HE, de Vries E, Soerjomataram I, Lemmens V, Siesling S, Coebergh JW. Recent trends of cancer in Europe: a combined approach of incidence, survival and mortality for 17 cancer sites since the 1990s. Eur J Cancer. 2008;44(10):1345-89.

[6] Cancer incidence by age: Cancer Research UK. Available from: http://www.cancerresearchuk.org/healthprofessional/cancer-statistics/incidence/age\#heading-Zero. Accessed June 2018.

[7] de Boer AG, Taskila TK, Tamminga SJ, Feuerstein M, Frings-Dresen $\mathrm{MH}$, Verbeek JH. Interventions to enhance return-to-work for cancer patients. Cochrane Database Syst Rev. 2015;9:CD007569.

[8] Duijts SFA, van Egmond MP, Gits M, van der Beek AJ, Bleiker EM. Cancer survivors' perspectives and experiences regarding behavioral determinants of return to work and continuation of work. Disabil Rehabil. 2016:1-9.

[9] Main DS, Nowels CT, Cavender TA, Etschmaier M, Steiner JF. A qualitative study of work and work return in cancer survivors. Psychooncology. 2005;14(11):992-1004.

[10] Amir Z, Neary D, Luker K. Cancer survivors' views of work 3 years post diagnosis: a UK perspective. Eur J Oncol Nurs. 2008;12(3):190-7.

[11] Kennedy F, Haslam C, Munir F, Pryce J. Returning to work following cancer: a qualitative exploratory study into the experience of returning to work following cancer. Eur $\mathbf{J}$ Cancer Care. 2007;16(1):17-25.

[12] Bains M, Yarker J, Amir Z, Wynn P, Munir F. Helping cancer survivors return to work: what providers tell us about the challenges in assisting cancer patients with work questions. J Occup Rehabil. 2012;22(1):71-7.

[13] de Boer AG, Bruinvels DJ, Tytgat KM, Schoorlemmer A, Klinkenbijl JH, Frings-Dresen MH. Employment status and work-related problems of gastrointestinal cancer patients at diagnosis: a cross-sectional study. BMJ Open. 2011;1(2):e000190.

[14] Bains M, Munir F, Yarker J, Steward W, Thomas A. Returnto-work guidance and support for colorectal cancer patients: a feasibility study. Cancer Nurs. 2011;34(6):E1-12.

[15] Nieuwenhuijsen K, Bos-Ransdorp B, Uitterhoeve LL, Sprangers MA, Verbeek JH. Enhanced provider communication and patient education regarding return to work in cancer survivors following curative treatment: a pilot study. J Occup Rehabil. 2006;16(4):647-57.

[16] Tamminga SJ, de Boer AG, Bos MM, Fons G, Kitzen JJ, Plaisier PW, et al. A hospital-based work support intervention to enhance the return to work of cancer patients: a process evaluation. J Occup Rehabil. 2012;22(4):565-78. 
[17] Tamminga SJ, Hoving JL, Frings-Dresen MH, de Boer AG. Cancer@Work - a nurse-led, stepped-care, e-health intervention to enhance the return to work of patients with cancer: study protocol for a randomized controlled trial. Trials. 2016;17(1):453.

[18] Zaman A, Tytgat K, van Hezel S, Klinkenbijl JHG, de Boer A, Frings-Dresen MHW. Development of a tailored work-related support intervention for gastrointestinal cancer patients. Eur J Cancer Care. 2018;27(2):e12782.

[19] Zaman AG, Tytgat KM, Klinkenbijl JH, Frings-Dresen $\mathrm{MH}$, de Boer AG. Design of a multicentre randomized controlled trial to evaluate the effectiveness of a tailored clinical support intervention to enhance return to work for gastrointestinal cancer patients. BMC cancer. 2016; 16:303.

[20] Ferlay J, Soerjomataram I, Dikshit R, Eser S, Mathers C, Rebelo M, et al. Cancer incidence and mortality worldwide: sources, methods and major patterns in GLOBOCAN 2012. Int J Cancer. 2015;136(5):E359-86.

[21] Orsmond GI, Cohn ES. The Distinctive Features of a Feasibility Study: Objectives and Guiding Questions. OTJR. 2015;35(3):169-77.

[22] Bowen DJ, Kreuter M, Spring B, Cofta-Woerpel L, Linnan $\mathrm{L}$, Weiner $\mathrm{D}$, et al. How we design feasibility studies. Am J Prev Med. 2009;36(5):452-7.

[23] Proctor EK, Landsverk J, Aarons G, Chambers D, Glisson C, Mittman B. Implementation research in mental health services: an emerging science with conceptual, methodological, and training challenges. Adm Policy Ment Health. 2009;36(1):24-34.

[24] Elo S, Kyngas $H$. The qualitative content analysis process. J Adv Nurs. 2008;62(1):1 07-15.
[25] Hsieh HF, Shannon SE. Three approaches to qualitative content analysis. Qual Health Res. 2005;15(9):1277-88.

[26] Tong A, Sainsbury P, Craig J. Consolidated criteria for reporting qualitative research (COREQ): a 32-item checklist for interviews and focus groups. Int J Qual Health Care. 2007;19(6):349-57.

[27] Petersen KS, Momsen AH, Stapelfeldt CM, Olsen PR, Nielsen CV. Return-to-work intervention during cancer treatment - The providers' experiences. Eur J Cancer Care. 2018;27(2):e12793.

[28] Hoefsmit N, Houkes I, Nijhuis FJ. Intervention characteristics that facilitate return to work after sickness absence: a systematic literature review. J Occup Rehabil. 2012;22(4):462-77.

[29] Knott V, Zrim S, Shanahan EM, Anastassiadis P, Lawn S, Kichenadasse G, et al. Returning to work following curative chemotherapy: a qualitative study of return to work barriers and preferences for intervention. Support Care Cancer. 2014;22(12):3263-73.

[30] Kiasuwa Mbengi R, Otter R, Mortelmans K, Arbyn M, Van Oyen $\mathrm{H}$, Bouland $\mathrm{C}$, et al. Barriers and opportunities for return-to-work of cancer survivors: time for action-rapid review and expert consultation. Syst Rev. 2016;5:35.

[31] Wells M, Williams B, Firnigl D, Lang H, Coyle J, Kroll T, et al. Supporting 'work-related goals' rather than 'return to work' after cancer? A systematic review and meta-synthesis of 25 qualitative studies. Psychooncology. 2013;22(6):1208-19.

[32] Murphy KM, Nguyen V, Shin K, Sebastian-Deutsch A, Frieden L. Health Care Professionals and the EmploymentRelated Needs of Cancer Survivors. J Occup Rehabil. 2017;27(2):296-305. 


\section{Appendix 1}

\section{Selected questions feasibility questionnaire}

\section{Selected questions from the patient questionnaire}

What did you think of the duration of the work-related meetings?

\begin{tabular}{|c|c|c|c|c|}
\hline & Just right & Too short & Too long & Not applicable \\
\hline First meeting & $\square$ & $\square$ & $\square$ & $\square$ \\
\hline Second meeting & $\square$ & $\square$ & $\square$ & $\square$ \\
\hline Third meeting & $\square$ & $\square$ & $\square$ & $\square$ \\
\hline
\end{tabular}

What did you think of the timing of the first meeting?
About right
$\square \quad$ Too early
$\square$ Too late

Explanation

Did you experience the work-related support as useful?
$\square$ Yes
$\square \quad$ Fairly useful
$\square \quad$ Neutral
$\square \quad$ Not really
$\square \quad$ No

Can you indicate what you found useful about the work-related support?

Can you indicate what you did not find useful about the work-related support?

Are you satisfied with the healthcare professional who supported you with the problems which are/were hindering your ability to work?

$\square$ Yes

$\square \quad$ No

Explanation 
Selected questions from the healthcare professionals' questionnaire:

How did you feel in the role of healthcare professional supporting patients with work-related problems?
Good
$\square \quad$ Neutral
$\square \quad$ Uncertain
$\square \mathrm{Bad}$

Can you elaborate on this?

What did you think of the timing of the first meeting (before treatment began)?
About right
$\square \quad$ Too early
$\square \quad$ Too late

Can you elaborate on this?

Did you use the decision diagram to see if the support was appropriate or if the patient should be referred to another type of support?

No - please explain why not

$\square$ Yes

Was the diagram user- friendly?

$\square$ Yes

$\square$ No - why not?

Did you refer a patient to another type of support?

$\square$ Yes

$\square$ No

Was it possible as an oncological occupational physician/oncology nurse to provide tailored support in the clinical setting?

$\square \quad$ Yes

$\square \quad$ No

- Why not? Can you give an example?

Do you have any recommendations to improve this intervention?
$\square \quad$ No
$\square \quad$ Yes

What should be different?

$\square \quad$ How could we resolve that in the future?

Recommendations 


\section{Appendix 2}

\section{Factors included in the decision diagram}

\begin{tabular}{|c|c|c|c|}
\hline $\begin{array}{l}\text { Healthcare } \\
\text { professional }\end{array}$ & A (oncology nurse) & $\begin{array}{l}\text { B (oncological occupational } \\
\text { physician) }\end{array}$ & C (multidisciplinary team) \\
\hline 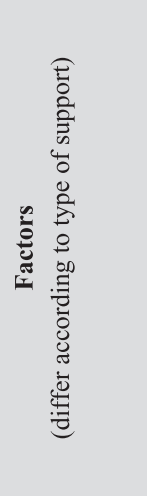 & $\begin{array}{l}\text { - } \text { Fatigue } \\
\text { - } \text { Pain } \\
\text { - Treatment } \\
\text { - Uncertainty about the } \\
\text { future } \\
\text { - Lack of support from } \\
\text { family and friends }\end{array}$ & $\begin{array}{l}\text { - Lack of workplace } \\
\text { support } \\
\text { Neuropsychological } \\
\text { symptoms } \\
\text { Occurrence of side } \\
\text { effects that prevent } \\
\text { patients from doing } \\
\text { current work } \\
\text { Combination of the } \\
\text { following factors: } \\
\text { number of working } \\
\text { hours - treatment - } \\
\text { stage of cancer and } \\
\text { fatigue }\end{array}$ & $\begin{array}{l}\text { Combination of the } \\
\text { following factors: } \\
\text { medical complications - } \\
\text { fatigue - stage of cancer } \\
\text { - type of cancer - } \\
\text { perception of change } \\
\text { regarding work - dietary } \\
\text { problems }\end{array}$ \\
\hline
\end{tabular}

